\section{Variation in good behaviour}

\section{Ian J. Patterson}

\section{Animal Behaviour: Ecology and}

Evolution.

By C.J. Barnard.

Croom Helm/Wiley: 1983. Pp.339.

Hbk £17.95; pbk £8.95, \$21.50.

The Study of Animal Behaviour.

By Felicity Huntingford.

Chapman \& Hall: 1984. Pp.411.

Hbk f24.50, \$49.95; pbk £10.95, \$22.

THE many texts on animal behaviour published over the past ten years have increasingly reflected the growth of interest in functional and evolutionary aspects of the subject. In particular, the emphasis on individual genetic fitness, gene selection and the strategies which animals should pursue to maximize fitness has culminated in a number of specialist books on sociobiology and behavioural ecology.

C.J. Barnard draws back from this extreme. His title is well-chosen in that the first half of the book covers straightforward ethology (the physical basis for behaviour, external and internal causal factors, with genetic and environmental influences on development), while the second deals with behavioural ecology and evolution (habitat selection, foraging theory, anti-predator behaviour, mating strategies and social behaviour). A final chapter draws together the second half of the book through a discussion of the evolution of behaviour, including a rather puzzling return to kin selection and evolutionarily stable strategies which are covered previously in Chapter 3 .

The text is clearly written and easy to follow, although some rather complex examples (for instance the account of newt courtship on p.70) lack a sufficiently full explanation for readers not familiar with the original work. The lettered keys on figures are tedious to read and sometimes it is unreasonably difficult to extract information from them; on p.91, for example, the text must be related to letters in the figure through a translation in the legend. The references too would have profited from greater care. Some authors are cited by name, others by a superscript reference number, while a few authors named in the text do not appear in the reference list or lack the usual superscript. Also, pertinent information sometimes appears without any reference at all (in Section 1.2.1. for example). Such sloppy presentation will frustrate the serious student anxious to follow up examples in detail.

These minor problems, however, do not detract seriously from what is an excellent and well-written undergraduate text. Animal Behaviour gives a good overview of the current state of play in this discipline

Huntingford's approach is the omission of the customary chapters on neuroanatomy and physiology and the structure and function of sense organs. It can be argued that knowledge of such "hardware" is not essential to an understanding of ethology, but most lecturers nevertheless include at least some coverage of the physical basis of behaviour in their courses and so may be reluctant to use this book as a sole text. Included in it, however, are very useful discussions of the description and measurement of behaviour and applied ethology, which add to the undoubted value of The Study of Animal Behaviour for student use.

Ian J. Patterson is a Senior Lecturer in Zoology at Culterty Field Station, University of Aberdeen.

Perhaps the most radical aspect of

\section{Monkey business}

\section{W. C. McGrew \&}

\section{J. R. Anderson}

\section{Primate Social Relationships:}

An Integrated Approach.

Edited by Robert A. Hinde.

Blackwell Scientific/Sinauer: 1983.

Pp.384. $H b k$ £26, \$40;

pbk $£ 13.80, \$ 21$.

Primate Behavior.

Edited by James L. Fobes and

James E. King.

Academic: 1983. Pp.393. \$29, £20.50.

Primate Social Relationships is an exciting book, both in content and in form. In content it is virtually unique for an anthology in that it is unified by a theoretical framework, the aim being to apply the ideas of Professor Hinde and his students at Cambridge to the analysis of social organization. Social life is seen as a hierarchical system of increasing complexity: individuals behave; when they exchange behaviour they interact; accumulated interactions lead to relationships; networks of relationships yield social structure. The key level in the system is the relationship, and the analyses provide both proximate and ultimate explanations.

The testing of the ideas has been done largely by research on three types of Old World monkeys: savanna baboons, vervet monkeys and rhesus macaques. The macaques have been subject to most attention, both in small harem groups in captivity and in a free-ranging population in Puerto Rico. Concentration on these polygynous forms is both a help and a hindrance, however, for while their nearuniformity of social organization allows confident, detailed conclusions to be drawn it prevents generalizations to other primates. To some degree, extension to other forms is tackled in the final chapter, but this is something of a hodge-podge and has the appearance of being an afterthought.
The novelty of the book's form lies in the fact that each chapter comprises from two to ten independent contributions. There are 61 such "mini-chapters", averaging about five pages each; about a third are conceptual in nature, the remainder empirical. Mostly these give concise, specific examples of, for instance, the effects of being orphaned, differences between primiparous and multiparous mothers, matriline membership and acquisition of social rank etc. Given that there are 20 contributors in all, the overall degree of clarity is remarkable, though a few sections read like abstracts of whole chapters from PhD theses.

Primate Behavior is a more conventional piece of compilation, consisting of eleven chapters on various topics in behavioural primatology with an acknowledged bias towards laboratory studies. It will therefore be used best in conjunction with other texts which cover ecology and social relations in greater depth. There are two chapters devoted to these areas, but understandably they suffer from having too much to say in too little space, and so such topics as territoriality, the effects of plant secondary compounds on feeding strategies, and infanticide are illustrated only modestly.

If the two contributions on naturalistic behaviour are better seen as appetisers for field studies than as main courses, two chapters by the editors on learning abilities constitute major reviews of experimental research on primate cognitive processes. Starting from simple conditioning, the authors trace developments in discrimination and reversal learning, learning set and delayed response, to more complex types of performance involving concepts of quantity and analogical reasoning. Object permanence, tool-use and cognitive maps are also discussed. An important point made here is that there has been a shift away from searching for single performance indices for categorizing different species according to "intelligence" to trying to understand the strategies which primates apply to 